\title{
Biochemical Studies on The Effect of Some Biologically Active Compounds on The Complication of Diabetes
}

\author{
Fathy Faheim A El-Latif ${ }^{1}$, Salama Rabiea ${ }^{2}$, Ahmed M Okasha ${ }^{2}$, Sahar M. I. Elgarhy ${ }^{1}$ and \\ Shaaban K Mohamed ${ }^{3 *}$ \\ ${ }^{1}$ Department of Chemistry, University of Elminia, Egypt
}

${ }^{2}$ Department of Biochemistry, University of Elminia, Egypt

${ }^{3}$ Chemistry and Environmental Division, Manchester Metropolitan University, UK

*Corresponding author: Shaaban K Mohamed, Chemistry and Environmental Division, Manchester Metropolitan University, Manchester, M1 5GD, UK.

To Cite This Article: Fathy Faheim A El-Latif, Salama Rabiea, Ahmed M Okasha, Sahar M. I. Elgarhy, Shaaban K Mohamed. Biochemical Studies on The Effect of Some Biologically Active Compounds on The Complication of Diabetes. Am J Biomed Sci \& Res. 2021 - 12(4). AJBSR. MS.ID.001766. DOI: 10.34297/AJBSR.2021.12.001766.

Received: 眥 March 19, 2020; Published: 眥 April 16, 2021

\begin{abstract}
Extract of green tea (GT), Proanthocyanidins (PACs) 95\% (Noxy life) which classified as a "dietary supplement" under the Dietary Supplement Health and Education and combination of them has been used to help normalize hyperglycemia level and delay sugar absorption so it delayed the complication of diabetes mellitus (diabetic nephropathy).These due to their high content of the active constituents, catechins, 1 - 5\% xanthine alkaloids (caffeine, theobromine, theophylline, xanthine) 20-30 \% flavonols; 3- 4\% flavonols and flavone-glycosides; about 5\% phenolic acids; 2$3 \%$ proanthocyanidins, $0.59-3.97 \%$ free amino acids; and minerals including significant amounts of aluminum, manganese, fluoride, and potassium.

Keywords: Extract of green tea (GT), Proanthocyanidins 95\% (PACs) Noxy life and Diabetic Nephropathy (DN)
\end{abstract}

\section{Introduction}

Diabetes mellitus is a serious metabolic disorder with micro and macro vascular complication that is defined by relative or absolute deficiency of insulin secretion. Today, diabetes is known to be one of the primary causes of mortality and morbidity in the world [1-3]. More than $10 \%$ of deaths are attributable to (DM) and its related complications in patients over 35 years old. Sustained hyperglycemia can damage the kidneys, nerves, heart and eyes [4]. Macro vascular (atherosclerotic) and micro vascular (nephropathy and retinopathy) disorders are the leading causes of morbidity and mortality in diabetic patients [5]. (DM) is generally comprised of several subcategories such as type 1 (DM) which demonstrated by absolute insulin deficiency caused by cell-specific autoimmune destruction of the insulin producing beta cells in the pancreas. Type 2 diabetes which is occurred as a result of the weakness of beta cells to compensate for insulin secretion or selective loss of pancreatic beta cells due to viral infections or toxic injury leading to insulin insufficiency [6].
Diabetic kidney disease is one of the critical problems of diabetes mellitus which its prevalence has been increasing in worldwide [7]. Moreover, alleviation of oxidative stress with antioxidant therapy has been shown to ameliorate hypertension in several animal models [8]. Generally, chronic hyperglycemia increases oxidative stress factors followed by modifying the structure and function of proteins and lipids significantly. It also induces glycolxidation and peroxidation. Thus, hyperglycemia results to auto-oxidation of glucose, glycation of proteins and activation of polyol mechanism. Hyperglycemia-induced oxidative stress has been singled out as one of the main links between diabetes and diabetic complications. Therefore, hyperglycemia induces autoxidation of glucose and glycosylation of proteins by generation of free radicals thus, increases the reactive oxygen species (ROS) accompanied by a reduction in antioxidant activity which leads to the occurrence of oxidative stress. These can cause endothelial dysfunction, insulin resistance, and alterations in the proportion and functions of 
pancreatic $\beta$ cells and ultimately leads to diabetic micro vascular and macro vascular complications [9]. Suggest a role for oxidative stress via an increased formation of reactive oxygen species (ROS) the primary antioxidant enzyme system includes Catalase (CAT), Glutathione reduced (GSH) and Malondialdehyde (MDA). Oxidative stress is a constant feature of uncontrolled diabetes in humans and animals $[10,11]$.

Green tea is one of the most popular beverages in the world where about three billion $\mathrm{kg}$ of tea are produced and consumed yearly [12]. (GT) contains polyphenols, which may account for up to $30 \%$ of the dry weight, but the most common green tea polyphenols are flavanoids, commonly called catechins [13]. Its compounds may influence glucose metabolism by several mechanisms, such as inhibition of carbohydrate digestion and glucose absorption in the intestine, stimulation of insulin secretion from the pancreatic B cells, modulation of glucose release from liver, activation of insulin receptors (enhancing insulin binding) and glucose uptake in the insulin-sensitive tissues, and modulation of hepatic glucose output [14]. Proanthocyanidins (PACs) is known as condensed tannin, a member of a specific group of polyphenolic compounds, and it has been reported to exhibit powerful antioxidant activity [15].

\section{Experimental Section}

Fifty adult male healthy albino rats weighing (200 - 220) gm, were randomly divided into 5 groups, 10 rats each group:

a. Group (1): Normal rats or negative control group.

b. Group (2): Served as positive control that lift without diet over night before Alloxan injection.

c. Group (3): Were given (GT) in dose 10 gm of dry green tea was added to $750 \mathrm{ml}$ of deionized boiled water cooled to $90 \mathrm{Co}$, brewed for 3minute, decanted vacuum filtered, placed on Ice and protected from light with aluminum foil. Rats drank $~ 100 \mathrm{ml}$ / day for one week before the induction with alloxan and for 6 weeks the period of the experiment.

d. Group (4): animals were given (PACs) (95\%) powder in dose of $50 \mathrm{mg}$ body wt. mixed with drinking water daily for one week before the induction with alloxan and for 6 weeks the period of the experiment. Group (5): were given (GT) and (PACs) (95\%) at the same dose of green tea in third group and same dose of (PACs) (95 $\%$ ) in fourth group for one week before the induction with alloxan and for 6 weeks the period of the experiment. From the second group to the fifth group were injected with alloxan monohydrate in dose $70 \mathrm{mg}$ body wt. in sterile $(0.9 \%)$ Nacl intraperitoneally (I.P.) at once.

After 72 hour\& after one week of alloxan injection, blood samples were collected from the tail vein of rats and blood glucose was determined by (one touch method). Rats with blood glucose above $250 \mathrm{mg} / \mathrm{dl}$ were considered diabetic while rats with blood glucose under $200 \mathrm{mg} / \mathrm{dl}$ were excluded so the blood samples were collected again after one week after alloxan injection and determined the blood glucose by same method (one touch) to ensure that the rats still diabetic. Finally, groups of rats from the second to the fifth were become diabetic after alloxan induction, while groups from the third to the fifth were given treatment doses before the induction with alloxan and for one week as prophylaxes and 6 weeks the duration of the experiment.

At the end of the experiment (After 6 weeks) animals were scarified and the blood was collected from the heart and centrifuged to obtain serum which collected for determine Blood Glucose test, Blood urea, serum creatinine, Serum sodium, Serum Potassium and Determination of Tumor Necrosis Factor- $\alpha$ (TNF- $\alpha$ ) (ELISA): The kidney also was removed and bisected longitudinally in to two halves. The first half was used for histopathological examinations \& the second part of kidney was homogenized to estimate (GSH), (CAT) and (MDA) (Table 1-9). (Figure 1).

Effect of dry GT (10gm), PACs 95\% (Noxy life) 50mg/kg body weight/day and combination of doses of GT with PACs 95\% (Noxy life) on blood glucose level in diabetic rats. Serum was obtained from diabetic rats were treated after 6 weeks. The mean blood glucose level in normal group was found to be $136.3 \pm 4.3 \mathrm{mg} / \mathrm{dl}$ there was a highly significant difference between normal and diabetic group by $115.8 \%$ which reached $294.2 \pm 27 \mathrm{mg} / \mathrm{dl} \mathrm{p}=0.001^{* *}$. Treatment of diabetic rats with green tea, PACs 95\% (Noxy life) and combination of them for 6 weeks results in a decrease in blood glucose level by $23.1 \%, 28.02 \%$ and $16.8 \%$ respectively which reached $167.9 \pm 6.1$ $\mathrm{mg} / \mathrm{dl} \mathrm{p}=0.001^{* *}, 174.5 \pm 6.3 \mathrm{mg} / \mathrm{dl} \mathrm{P}=0.001^{* *}$ and $159.2 \pm 11.9 \mathrm{mg} /$ dl $\mathrm{P}=0.001^{* *}$ respectively (Table 1 \& Figure 1 ).

Table 1: Comparison of blood glucose level between the studied groups.

\begin{tabular}{|c|c|c|c|c|c|}
\hline Blood Glucose Mg/DI & Control NO=10 & Diabetics NO=10 & Green Tea NO=10 & PACs NO=10 & $\begin{array}{c}\text { Green Tea and PACs } \\
\text { NO=10 }\end{array}$ \\
\hline Range & $130-145$ & $225-315$ & $160-175$ & $170-179$ & $150-180$ \\
\hline Mean \pm SD & $136.3 \pm 4.3$ & $294.2 \pm 27.4$ & $167.9 \pm 6.1$ & $174.5 \pm 6.3$ & $159.2 \pm 11.9$ \\
\hline P value & & $0.001^{* *}$ & $0.001^{* *}$ & $0.001^{* *}$ & $0.001^{* *}$ \\
\hline \% of change & & $115.80 \%$ & $23.10 \%$ & $28.02 \%$ & $16.80 \%$ \\
\hline
\end{tabular}




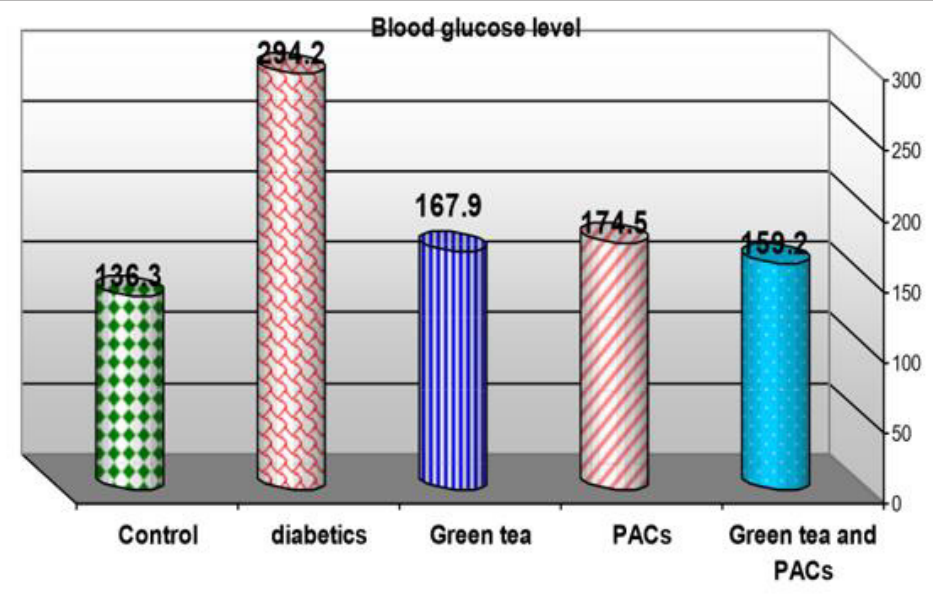

Figure 1: Comparison of blood glucose level between the studied groups.

Effect of dry GT (10gm), PACs 95\% (Noxy life) 50mg/kg body weight/day and combination of doses of GT with PACs 95\% (Noxy life) on blood urea level in diabetic rats. Serum was obtained from diabetic rats were treated after 6 weeks. The mean blood urea level in normal group was found to be $32.9 \pm 6.8 \mathrm{mg} / \mathrm{dl}$ there was a highly significant difference between normal and diabetic group by $193.9 \%$ which reached $96.7 \pm 7.6 \mathrm{mg} / \mathrm{dl} \mathrm{p}=0.001^{* *}$. Treatment of diabetic rats with green tea, PACs $95 \%$ (Noxy life) and combination of them for 6 weeks results in a decrease in blood glucose level by $45.8 \%, 78.4 \%$ and $24.01 \%$ respectively which reached $48 \pm 2 \mathrm{mg} /$ $\mathrm{dl} \mathrm{p}=0.001^{* *}, 58.7 \pm 4.2 \mathrm{mg} / \mathrm{dl} \mathrm{P}=0.001^{* *}$ and $40.8 \pm 4.6 \mathrm{mg} / \mathrm{dl}$ $\mathrm{P}=0.007^{* *}$ respectively (Table 2 \& Figure 2 ).

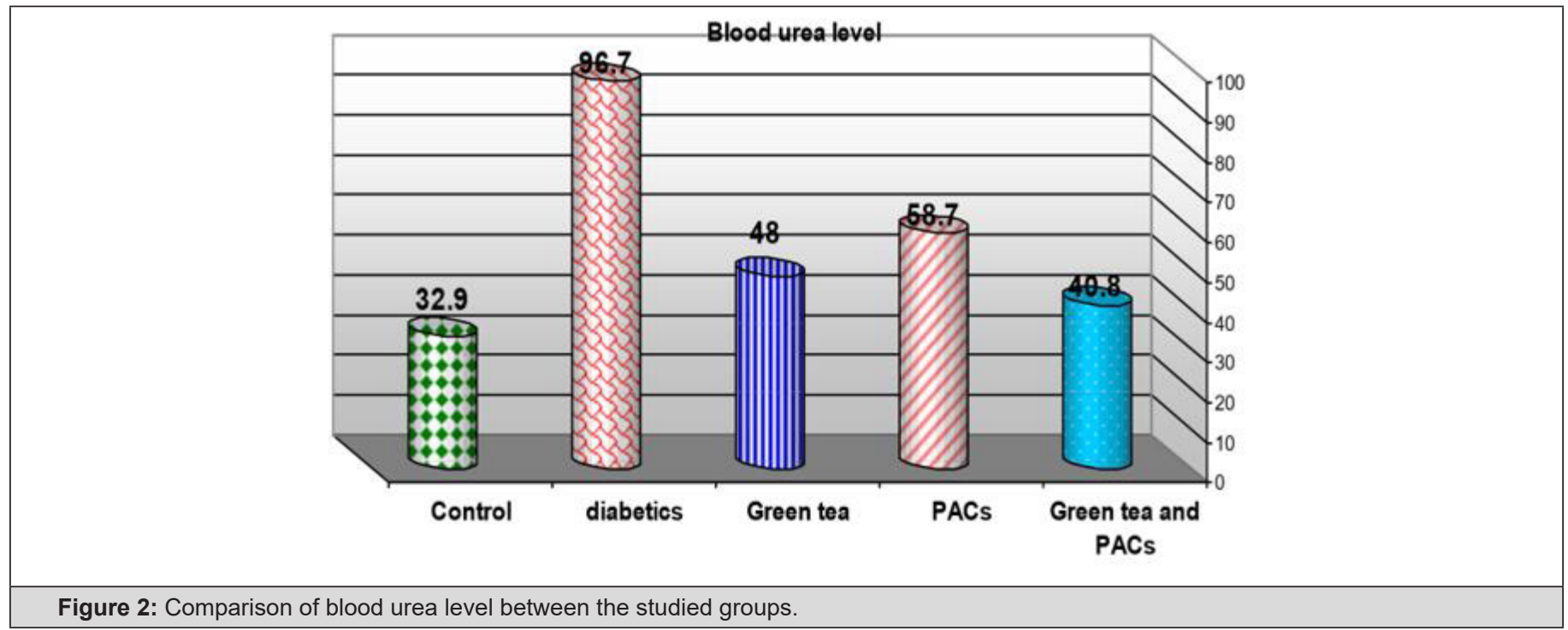

Table 2: Comparison of blood urea level between the studied groups.

\begin{tabular}{|c|c|c|c|c|c|}
\hline Blood Urea Mg/Dl & Control & Diabetics & Green Tea & PACs & Green Tea and PACs \\
\hline Range & $19-40$ & $85-109$ & $45-50$ & $50-56$ & $35-50$ \\
\hline Mean \pm SD & $32.9 \pm 6.8$ & $96.7 \pm 7.6$ & $48 \pm 2$ & $58.7 \pm 4.2$ & $40.8 \pm 4.6$ \\
\hline P value & & $0.001^{* *}$ & $0.001^{* *}$ & $0.001^{* *}$ & $0.007^{* *}$ \\
\hline \% of change & & $193.90 \%$ & $45.80 \%$ & $78.40 \%$ & $24.01 \%$ \\
\hline
\end{tabular}

Effect of dry GT (10gm), PACs 95\% (Noxy life) 50mg/kg body weight/day and combination of doses of GT with PACs 95\% (Noxy life) on serum creatinine level in diabetic rats. Serum was obtained from diabetic rats were treated after 6 weeks. The mean serum creatinine level in normal group was found to be $0.7 \pm 0.09 \mathrm{mg} /$ $\mathrm{dl}$ there was a highly significant difference between normal and diabetic group by $228.5 \%$ which reached $2.3 \pm 0.3 \mathrm{mg} / \mathrm{dl} \mathrm{p}=0.001^{* *}$. Treatment of diabetic rats with green tea, PACs 95\% (Noxy life) and combination of them for 6 weeks results in a decrease in blood glucose level by $128.5 \%, 128.5 \%$ and $71.4 \%$ respectively which reached $1.6 \pm 0.2 \mathrm{mg} / \mathrm{dl} \mathrm{p}=0.001^{* *}, 1.6 \pm 0.2 \mathrm{mg} / \mathrm{dl} \mathrm{P}=0.001^{* *}$ and $1.2 \pm 0.3 \mathrm{mg} / \mathrm{dl} \mathrm{P}=0.001^{* *}$ respectively (Table 3 \& Figure 3 ). 


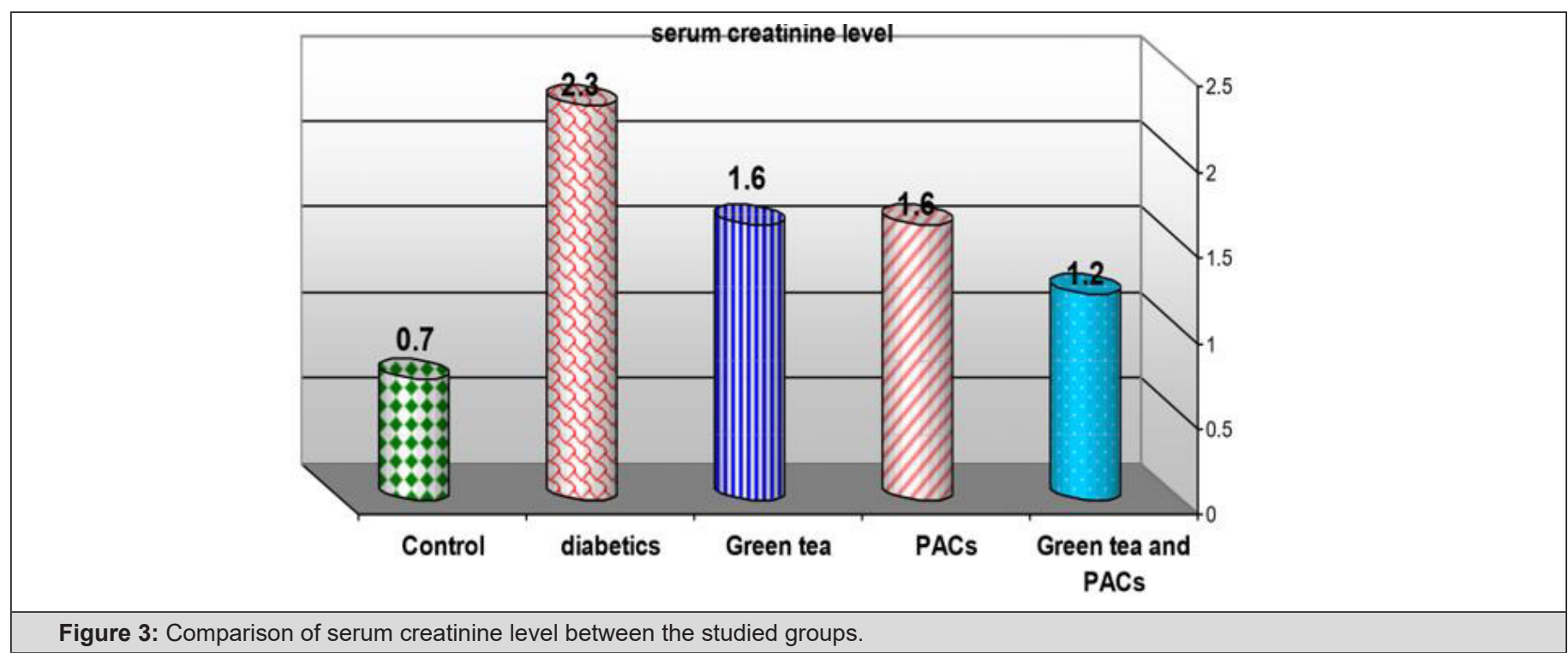

Figure 3: Comparison of serum creatinine level between the studied groups.

Table 3: Comparison of serum creatinine level between the studied groups.

\begin{tabular}{|c|c|c|c|c|c|}
\hline Serum creatinine $\mathbf{m g} / \mathbf{d l}$ & Control & Diabetics & Green tea & PACs & Green Tea and PACs \\
\hline Range & $0.7-1$ & $1.85-2.8$ & $0.95-1.9$ & $1.2-2$ & $0.82-1.8$ \\
\hline Mean \pm SD & $0.7 \pm 0.09$ & $2.3 \pm 0.3$ & $1.6 \pm 0.2$ & $1.6 \pm 0.2$ & $1.2 \pm 0.3$ \\
\hline P value & & $0.001^{* *}$ & $0.001^{* *}$ & $0.001^{* *}$ & $0.001^{* *}$ \\
\hline \% of change & & $288.50 \%$ & $128.50 \%$ & $128.50 \%$ & $71.40 \%$ \\
\hline
\end{tabular}

Effect of dry (GT) (10gm), PACs 95\% (Noxy life) 50mg/kg body weight/day and combination of doses of GT with PACs 95\% (Noxy life) on serum sodium level in diabetic rats. Serum was obtained from diabetic rats were treated after 6 weeks. The mean serum sodium level in normal group was found to be $142.8 \pm 5.9 \mathrm{mmol} / \mathrm{L}$ there was a highly significant difference between normal and diabetic group by $29.2 \%$ which reached $184.5 \pm 6.8 \mathrm{mmol} / \mathrm{L} \mathrm{p}=$
0.001**. Treatment of diabetic rats with green tea, PACs 95\%(Noxy life) and combination of them for 6 weeks results in a decrease in blood glucose level by $11.6 \%, 18.1 \%$ and $8.8 \%$ respectively which reached $159.5 \pm 7.1 \mathrm{mmol} / \mathrm{L} \mathrm{p}=0.001^{* *}, 168.6 \pm 11.3 \mathrm{mmol} / \mathrm{L}$ $\mathrm{P}=0.001^{* *}$ and $155.4 \pm 8.08 \mathrm{mmol} / \mathrm{L} \mathrm{P}=0.001^{* *}$ respectively (Table 4 \& Figure 4).

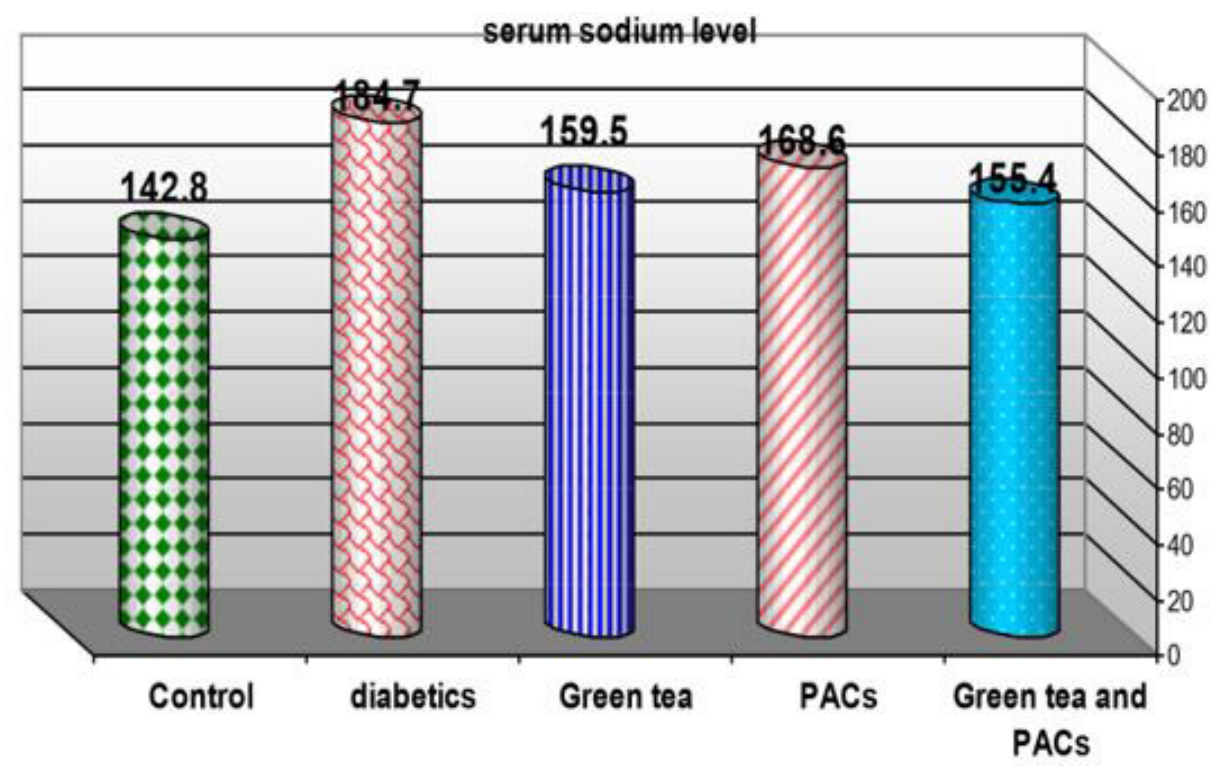

Figure 4: Comparison of serum sodium level between the studied groups. 
Table 4: Comparison of serum sodium level between the studied groups.

\begin{tabular}{|c|c|c|c|c|c|}
\hline Serum Sodium mmol/L & Control & Diabetics & Green tea & PACs & Green Tea and PACs \\
\hline Range & $136-152$ & $170-193$ & $150-170$ & $155-196$ & $135-163$ \\
\hline Mean \pm SD & $142.8 \pm 5.9$ & $184.5 \pm 6.8$ & $159.5 \pm 7.1$ & $168.6 \pm 11.3$ & $155.4 \pm 8.08$ \\
\hline P value & & $0.001^{* *}$ & $0.001^{* *}$ & $0.001^{* *}$ & $0.001^{* *}$ \\
\hline \% of change & & $29.20 \%$ & $11.60 \%$ & $18.10 \%$ & $8.80 \%$ \\
\hline
\end{tabular}

Effect of dry GT (10gm), PACs 95\% (Noxy life) 50mg/kg body weight/day and combination of doses of GT with PACs $95 \%$ (Noxy life) on serum potassium level in diabetic rats. Serum was obtained from diabetic rats were treated after 6 weeks. The mean serum potassium level in normal group was found to be $4.3 \pm 0.5$ $\mathrm{mmol} / \mathrm{L}$ there was a highly significant difference between normal and diabetic group by $53.4 \%$ which reached $6.6 \pm 0.9 \mathrm{mmol} / \mathrm{L} \mathrm{p}=$ $0.001^{* *}$. Treatment of diabetic rats with green tea, PACs $95 \%$ (Noxy life) and combination of them for 6 weeks results in a decrease in blood glucose level by $18.3 \%, 37.2 \%$ and $18.1 \%$ respectively which reached $5.09 \pm 0.8 \mathrm{mmol} / \mathrm{L} \mathrm{p}=0.003^{* *}, 5.9 \pm 0.6 \mathrm{mmol} / \mathrm{L} \mathrm{p}=0.001^{* *}$ and $5.08 \pm 0.8 \mathrm{mmol} / \mathrm{L} \mathrm{P}=0.003^{* *}$ respectively (Table 5 \& Figure 5).

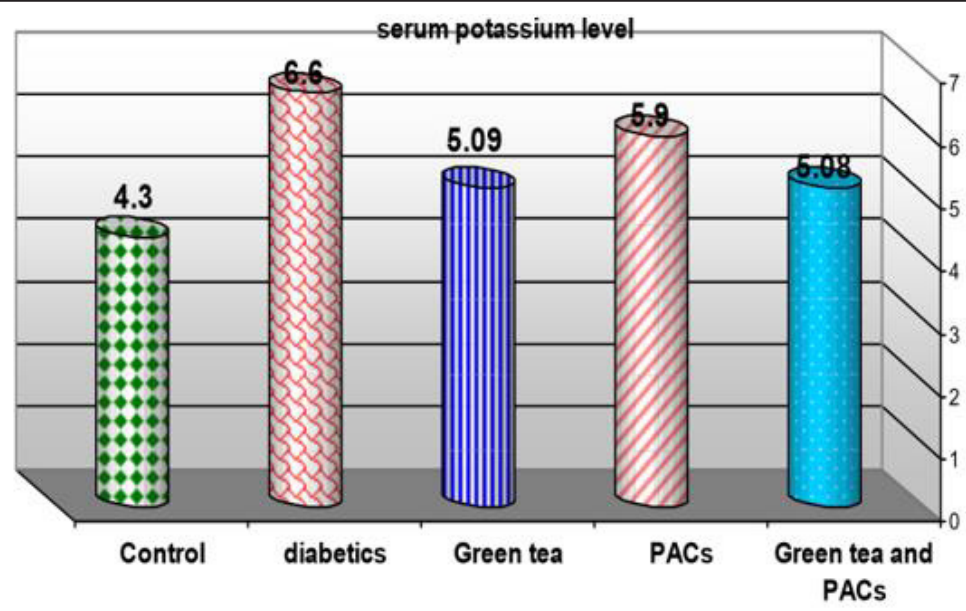

Figure 5: Comparison of serum potassium level between the studied groups.

Table 5: Comparison of serum potassium level between the studied groups.

\begin{tabular}{|c|c|c|c|c|}
\hline Serum Potassium mmol/L & Control & Diabetics & Green tea & Green Tea and PACs \\
\hline Range & $3.7-5.1$ & $5.5-8.9$ & $3.7-6$ & $5-7.2$ \\
\hline Mean \pm SD & $4.3 \pm 0.5$ & $6.6 \pm 0.9$ & $5.09 \pm 0.8$ & $5.9 \pm 0.6$ \\
\hline P value & & $0.001^{* *}$ & $0.03^{*}$ & $0.001^{* *}$ \\
\hline \% of change & & $53.40 \%$ & $18.30 \%$ & $37.20 \%$ \\
\hline
\end{tabular}

Effect of dry GT (10gm), PACs 95\% (Noxy life) 50mg/kg body weight/day and combination of doses of GT with PACs 95\% (Noxy life) on tissue glutathione reduced enzyme level in diabetic rats. Serum was obtained from diabetic rats were treated after 6 weeks. The mean tissue glutathione reduced enzyme level in normal group was found to be $50.1 \pm 2.3 \mathrm{mg} / \mathrm{g}$. tissue there was a highly significant difference between normal and diabetic group by $51.6 \%$ which Table 6: Comparison of Glutathione reduced enzyme (GSH) level (in tissue) between the studied groups.

\begin{tabular}{|c|c|c|c|c|}
\hline Serum Glutathione $\mathbf{m g} / \mathbf{g}$. tissue & Control & Diabetics & Green tea & Green Tea and PACs \\
\hline Range & $47.2-54$ & $18-30$ & $35.1-45$ & $36.5-40.9$ \\
\hline Mean \pm SD & $50.1 \pm 2.3$ & $24.2 \pm 3.1$ & $38.8 \pm 3.3$ & $38.4 \pm 1.4$ \\
\hline P value & & $0.001^{* *}$ & $0.001^{* *}$ & $0.001^{* *}$ \\
\hline \% of change & & $51.60 \%$ & $22.50 \%$ & $23.30 \%$ \\
\hline
\end{tabular}

reached $24.2 \pm 3.1 \mathrm{mg} / \mathrm{g}$. tissue $\mathrm{p}=0.001^{* *}$. Treatment of diabetic rats with green tea, PACs $95 \%$ (Noxy life) and combination of them for 6 weeks results in a decrease in blood glucose level by $22.5 \%$, $23.3 \%$ and $23.1 \%$ respectively which reached $38.8 \pm 3.3 \mathrm{mg} / \mathrm{g}$. tissue $\mathrm{p}=0.001^{* *}, 38.4 \pm 1.4 \mathrm{mg} / \mathrm{g}$. tissue $\mathrm{p}=0.001^{* *}$ and $38.5 \pm 2.3 \mathrm{mg} / \mathrm{g}$. tissue $\mathrm{P}=0.001^{* *}$ respectively (Table 6 \& Figure 6 ). 


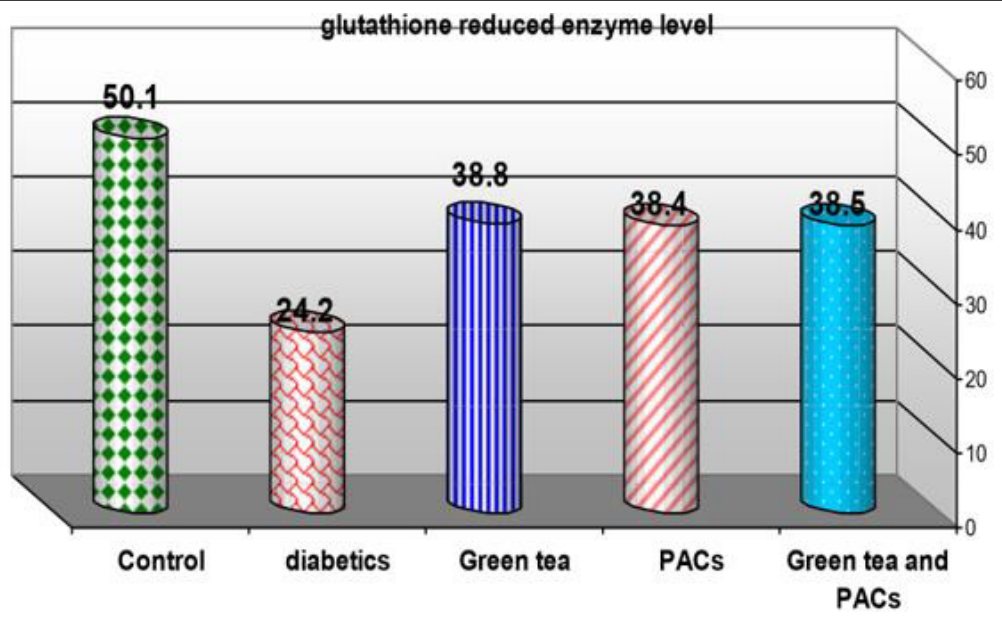

Figure 6: Comparison of Glutathione reduced enzyme level between the studied groups.

Effect of dry GT (10gm), PACs 95\% (Noxy life) $50 \mathrm{mg} / \mathrm{kg}$ body weight/day and combination of doses of GT with PACs 95\% (Noxy life) on tissue CAT enzyme level in diabetic rats. Serum was obtained from diabetic rats were treated after 6 weeks. The mean tissue CAT enzyme level in normal group was found to be $0.8 \pm 0.09 \mathrm{mg} / \mathrm{g}$. tissue there was a highly significant difference between normal and diabetic group by $50 \%$ which reached $0.4 \pm 0.05 \mathrm{mg} / \mathrm{g}$. tissue $p=0.001^{* *}$. Treatment of diabetic rats with GT, PACs 95\% (Noxy life) and combination of them for 6 weeks results in a decrease in blood glucose level by $16.2 \%, 17.5 \%$ and $18.7 \%$ respectively which reached $0.67 \pm 0.05 \mathrm{mg} / \mathrm{g}$. tissue $\mathrm{p}=0.001^{* *}, 0.66 \pm 0.06 \mathrm{mg} / \mathrm{g}$. tissue $\mathrm{p}=0.001^{* *}$ and $0.65 \pm 0.11 \mathrm{mg} / \mathrm{g}$. tissue $\mathrm{P}=0.005^{* *}$ respectively (Table 7 \& Figure 7).

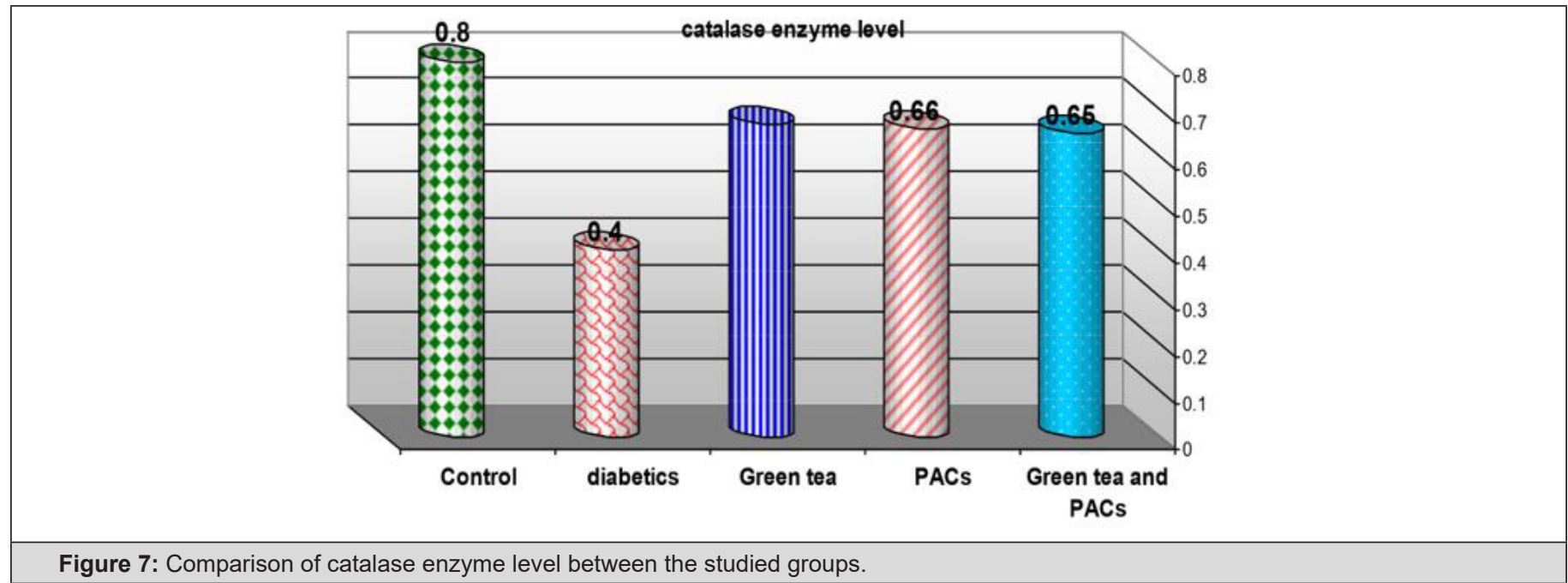

Table 7: Comparison of Catalase enzyme (CAT) level (in tissue) between the studied groups.

\begin{tabular}{|c|c|c|c|c|c|}
\hline Catalaze Enzyme Mg/G. Tissue & Control & Diabetics & Green Tea & PACs & Green Tea and PACs \\
\hline Range & $0.65-0.93$ & $0.40-0.60$ & $0.58-0.73$ & $0.56-0.79$ & $0.47-0.77$ \\
\hline Mean \pm SD & $0.8 \pm 0.09$ & $0.4 \pm 0.05$ & $0.67 \pm 0.05$ & $0.66 \pm 0.06$ & $0.65 \pm 0.11$ \\
\hline P value & & $0.001^{* *}$ & $0.001^{* *}$ & $0.001^{* *}$ & $0.005^{* *}$ \\
\hline$\%$ of change & & $50 \%$ & $16.20 \%$ & $17.50 \%$ & $18.70 \%$ \\
\hline
\end{tabular}

Effect of dry G T (10gm), PACs 95\% (Noxy life) 50mg/kg body weight/day and combination of doses of GT with PACs 95\% (Noxy life) on tissue MDA level in diabetic rats. Serum was obtained from diabetic rats were treated after GT 6 weeks. The mean tissue MDA level in normal group was found to be $37.4 \pm 3.6 \mathrm{mg} / \mathrm{g}$. tissue there was a highly significant difference between normal and diabetic group by $78.6 \%$ which reached $66.8 \pm 9.1 \mathrm{mg} / \mathrm{g}$. tissue $\mathrm{p}=0.001^{* *}$.
Treatment of diabetic rats with green tea, PACs 95\% (Noxy life) and combination of them for 6 weeks results in a decrease in blood glucose level by $20.1 \%, 32.3 \%$ and $9.01 \%$ respectively which reached $29.9 \pm 4.1 \mathrm{mg} / \mathrm{g}$. tissue $\mathrm{p}=0.001^{* *}, 25.3 \pm 2.6 \mathrm{mg} / \mathrm{g}$. tissue $\mathrm{p}=0.001^{* *}$ and $34.03 \pm 3.6 \mathrm{mg} / \mathrm{g}$. tissue $\mathrm{P}=0.05$ respectively (Table 8 \& Figure 8). 


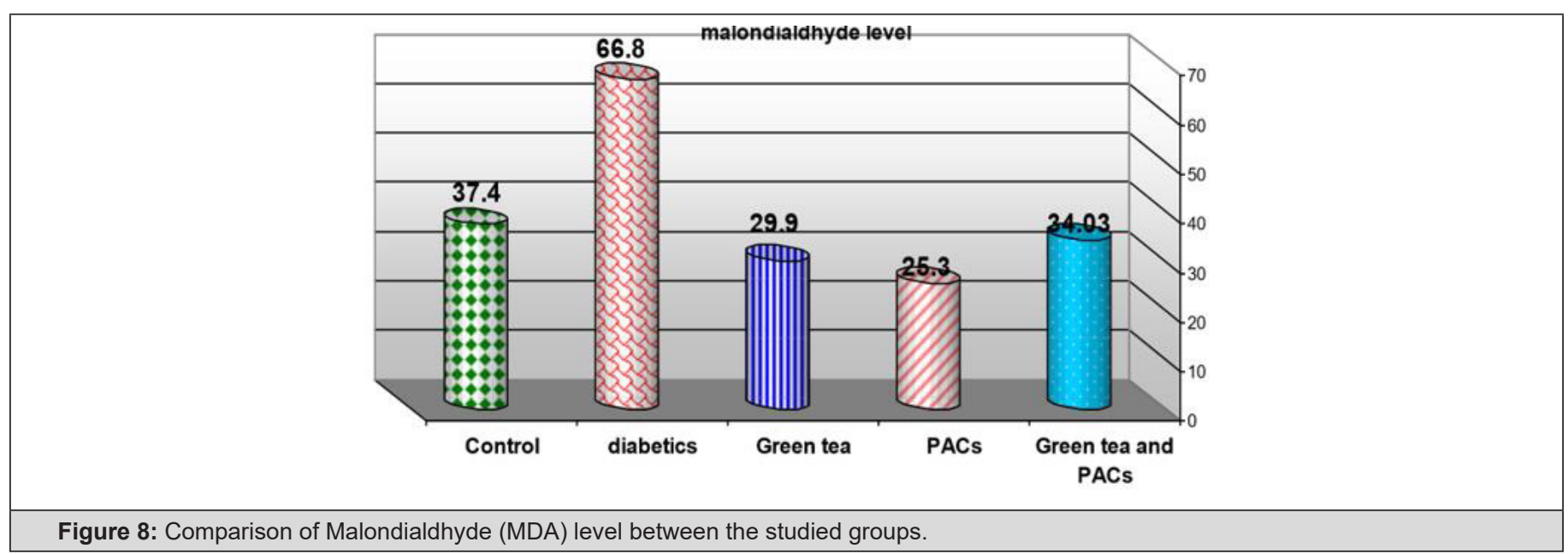

Table 8: Comparison of Malondialdhyde (MDA) level (in tissue) between the studied groups.

\begin{tabular}{|c|c|c|c|c|c|}
\hline Malondialdhyde $\mathbf{~ m g} /$ g.tissue & Control & Diabetics & Green tea & PACs & Green Tea and PACs \\
\hline Range & $31.7-45$ & $47-85$ & $24-37$ & $20.6-30$ & $28-39$ \\
\hline Mean \pm SD & $37.4 \pm 3.6$ & $66.8 \pm 9.1$ & $29.9 \pm 4.1$ & $25.3 \pm 2.6$ & $34.03 \pm 3.6$ \\
\hline P value & & $0.001^{* *}$ & $0.001^{* *}$ & $0.001^{* *}$ & 0.05 \\
\hline \% of change & & $78.60 \%$ & $20.10 \%$ & $32.30 \%$ & $9.01 \%$ \\
\hline
\end{tabular}

Effect of dry GT (10gm), PACs 95\% (Noxy life) 50mg/kg body weight/day and combination of doses of GT with PACs 95\% (Noxy life) on serum TNF- $\alpha$ level in diabetic rats. Serum was obtained from diabetic rats were treated after 6 weeks. The mean serum TNF $\alpha$ level in normal group was found to be $4.9 \pm 0.3 \mathrm{pg} / \mathrm{ml}$ there was a highly significant difference between normal and diabetic group by $67.3 \%$ which reached $8.2 \pm 0.3 \mathrm{pg} / \mathrm{ml} \mathrm{p}=0.001^{* *}$. Treatment of diabetic rats with GT, PACs $95 \%$ (Noxy life) and combination of them for 6 weeks results in a decrease in blood glucose level by $10.2 \%, 30.6 \%$ and $4.1 \%$ respectively which reached $5.4 \pm 0.9 \mathrm{pg} /$ $\mathrm{ml} \mathrm{p}=0.01,6.4 \pm 0.6 \mathrm{pg} / \mathrm{dl} \mathrm{p}=0.001^{* *}$ and $4.7 \pm 0.6 \mathrm{pg} / \mathrm{ml} \mathrm{P}=0.03$ respectively (Table $9 \&$ Figure 9).

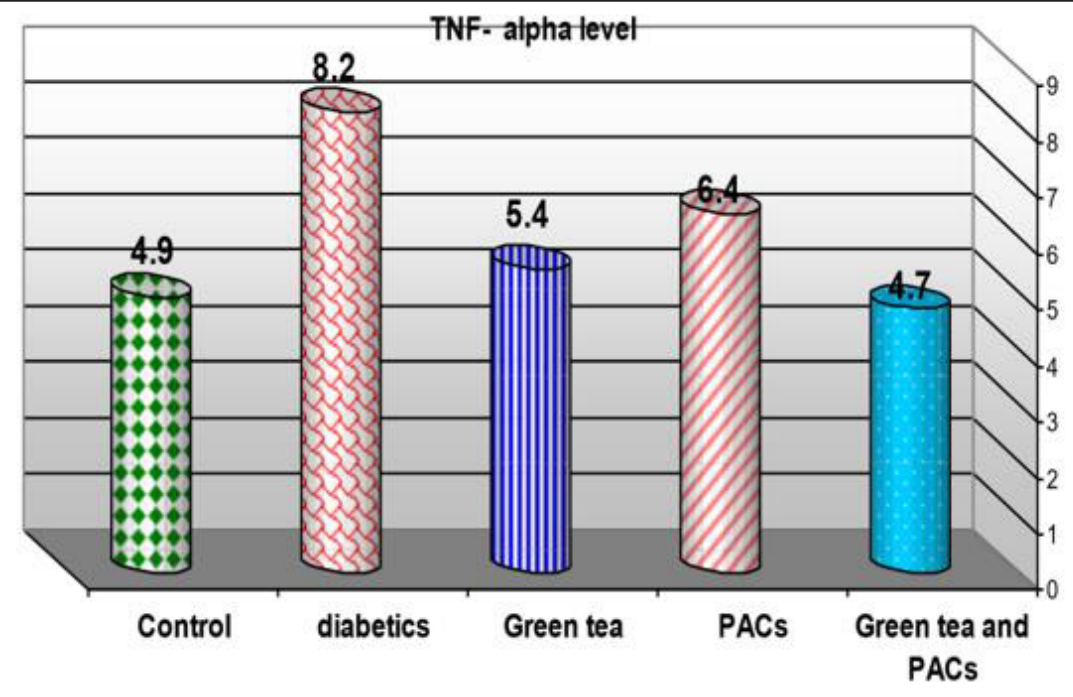

Figure 9: Comparison of SerumTNF- $\alpha$ level between the studied groups.

Table 9: Comparison of serum Tumor Necrosis Factor (TNF- $\alpha$ ) level between the studied groups.

\begin{tabular}{|c|c|c|c|c|c|}
\hline TNF- $\boldsymbol{\alpha} \mathbf{~ p g} / \mathbf{m l}$ & Control & diabetics & Green tea & PACs & Green Tea and PACs \\
\hline Range & $4.7-5.8$ & $7.8-8.9$ & $3.6-6.8$ & $5.1-7.3$ & $3.2-5.5$ \\
\hline Mean \pm SD & $4.9 \pm 0.3$ & $8.2 \pm 0.3$ & $5.4 \pm 0.9$ & $6.4 \pm 0.6$ & $4.7 \pm 0.6$ \\
\hline P value & & $0.001^{* *}$ & 0.1 & $0.001^{* *}$ & 0.3 \\
\hline \% of change & & $67.30 \%$ & $10.20 \%$ & $30.60 \%$ & $4.10 \%$ \\
\hline
\end{tabular}




\section{Histopathology}

i. A- represents a section in kidney from normal animal group and showed normal glomeruli formed of capillary tufts and surrounded by meningeal membrane (short arrow) and normal tubules lined by single layer of low cuboidal epithelial cells and they are empty (long arrow)

ii. B-represents a Section in kidney from animal group given alloxan and showed atrophic glomerulus (long arrow), wide meningeal space around glomeruli (blue arrow) cloudy swelling of renal tubules with hyaline casts (short arrow).

iii. C represents a Section in kidney from animal group given green tea with PACs 95\% (Noxy life) and showed thick blood vessels (long arrow), casts (blue arrow), hemorrhage (short arrow), dilated tubules with decreased cloudy swelling and healthy glomeruli (green arrow).

iv. D- represents a Section in kidney from animal group given green tea and showed Thick-walled blood vessels (short arrow), wide meningeal space (long arrow), cellular glomerulus with atrophy (blue arrow), area of hemorrhage (green arrow), the renal tubules showed less cloudy swelling.

v. E- represents a Section in kidney from animal group given PACs 95\% (Noxy life) and showed cloudy swelling of renal tubules (short arrow), lobulated glomerulus with widening of meningeal space (long Arrow), few inflammatory cellular infiltrates (blue arrow) (Figure 10).

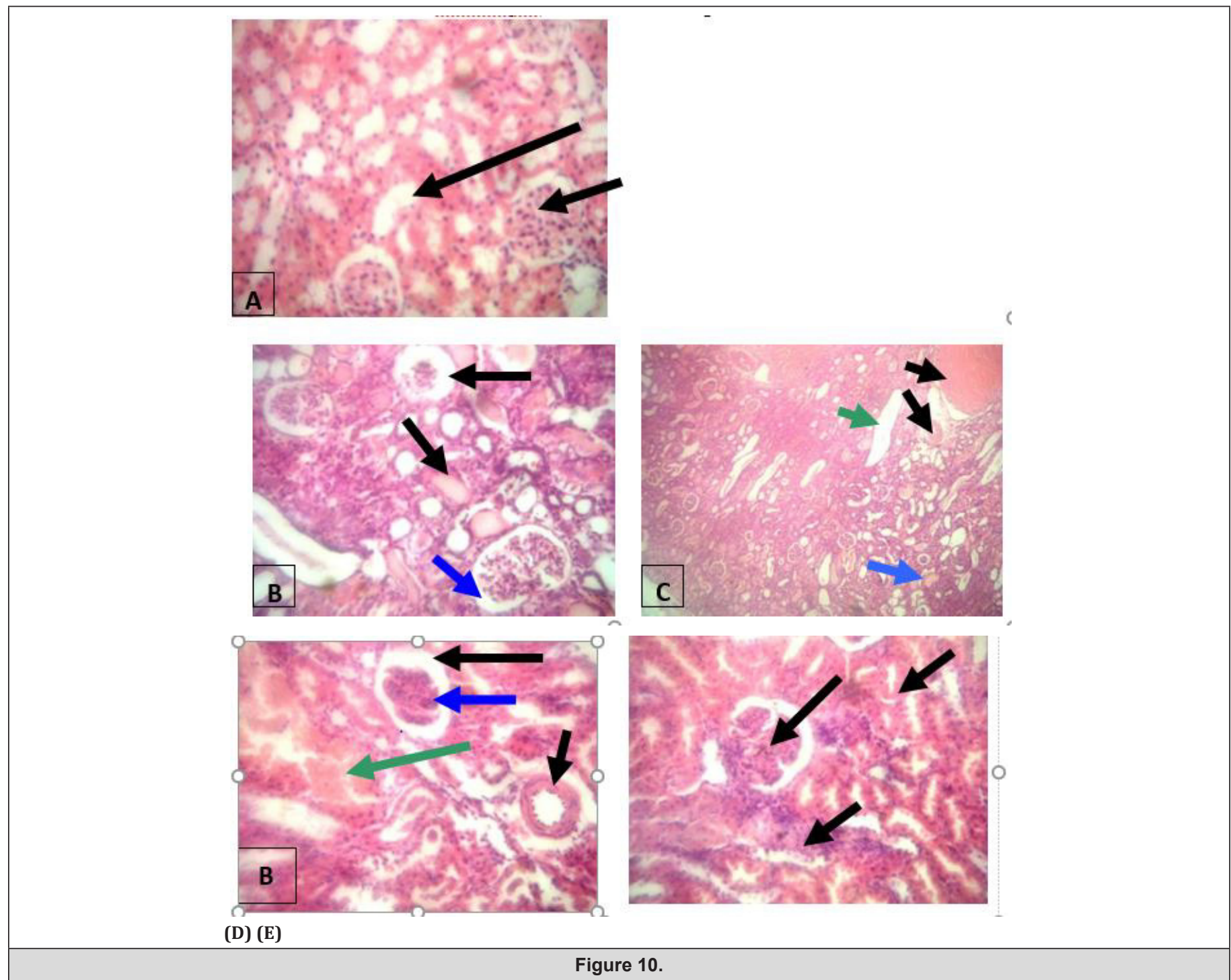

\section{Discussion}

This study reveals a number of important findings on the relationship between $\mathrm{DN}$, oxidant stress and the chronic consumption of GT, PACs and combination of them. As a poorly controlled long standing Metabolic disorders DM is frequently rustles in nephropathy and cardiovascular complications [7]. Moreover, alleviation of oxidative stress with antioxidant therapy has been shown to ameliorate hypertension in several animal 
models [8]. Induction of rats with alloxan resulted in a partial destruction of $\beta$ cells which resulted in the high glucose levels of the alloxan treated rats. Hyperglycemia leads to enhanced formation of advanced glycation and products (AGEP) and reactive oxygen species (ROS). This results in oxidative stress which enhances the pathogenesis of DN [16]. Our goal here is to study the effect of GT, pACs $95 \%$ (Noxy life) and their combination as hypoglycemic agents on the progression of diabetic nephropathy. The present study demonstrates that treatment of alloxan diabetic rats with dry GT leads to a significant reduction in blood glucose levels. The obtained data were in line with previous data from [17].

That GT contain a great amount of antioxidant chemical constituents as catechins, xanthine alkaloids (caffeine, xanthine theobromine, theophylline,) [12], flavonols; flavonols and flavoneglycosides, phenolic acids, PACs, free amino acids and including significant amounts of aluminum, manganese, fluoride, and potassium [13]. Also, PACs have approximately similar effect that it has also been shown to help normalize blood glucose (sugar) level. these data were in line with previous data from [18] and delay sugar absorption [19]. That PACs one of the constituents of GT, consist of catechins. Flavonoids which found in red wine, apples, maritime pine bark, cinnamon, cocoa beans, bilberry, cranberry, black currant, green tea, black tea, natural grape seed and grape skin [20]. So that the powder of red grapes seeds which is in capsules of PACs $95 \%$ (Noxy life), reach with PACs which considered antioxidant, antibacterial, antiviral, ant carcinogenic, anti-inflammatory, antiallergic, and vasodilator actions [15]. GT with PACs $95 \%$ (Noxy life) are considered strong antioxidants and the combination between them give a synergistic power. All the biochemical markers such as blood glucose level, blood urea, serum creatinine, sodium, potassium was improved.

Also, the lipid peroxidation (MDA) was reduced [21]. The antioxidant enzymes GSH, CAT was significantly increased, and these data were in line with [8]. In addition, TNF - $\alpha$ in serum was significantly reduced as a result of this treatment and these data were in line with [22]. The results which were obtained showed that Treatment of diabetic rats with the combination of GT with PACs leads to significant reduction in blood glucose levels and this could be attributed to its effect on the enzymes that digest carbohydrates and hence decrease glucose absorbance from intestine and these data were in line [23]. The synergistic power which resulted from this combination make the result better than GT or PACs alone. As PACs one of the constituents of GT so it had better result [24], than PA which also have strong antioxidants effect [25]. All of the previous, treatments (GT, PACs and GT with PACs) showed agreat modification in all previous biochemical markers compared to diabetic group.

This could be attributed to the pathogenesis of the rat kidney and the progression of diabetic nephropathy. Treatment of rats with (G T, PACs and GT with PA) was significantly improved all these parameters indicating their therapeutic potential. These data were in line with the other data obtained from histopathology. Pathology data: tubular cells are direct targets for enhanced glucose levels present in diabetes. Glucose uptake of tubular cells is independents of insulin, resulting in a direct relation of the plasma glucose concentration to the intracellular glucose level of tubular cells [26]. In addition, excess glucose in the glomerular filtrate leads to enhanced proximal tubular glucose efflux within the proximal tubule [27]. On exposure to glucose, tubular cells secrete vasoactive hormones like angiotensin II (due to the activation of the local intra renal renin - angiotensin system, transforming growth factor $\beta$ and matrix proteins [26]. Glucose-dependent metabolic pathways and vasoactive hormones may directly influence tubular and interstitial cells, leading to renal dysfunction caused by no glomerular mechanisms [26].

It has recently been demonstrated that high intracellular glucose levels lead to the enhanced formation of advanced glycation end products (AGEs), in particular carboxymethyllysine (CML) - modified proteins and the subsequent activation of the redox - sensitive transcription factor $\mathrm{NF}-\mathrm{kB}$ [28]. The effect of the treatment on the lipid peroxidation (MDA) in the kidney homogenate indicated that, the level of MDA was significantly reduced which indicate the reduction in the lipid peroxidation as a result of the treatment. Also, the antioxidant enzyme Catalase and were significantly increased as result of the treatment indicating the reduction of oxidative stress and ROS in the treated groups which may be attributed an antioxidant power of the three compounds. The degree of inflammations in the kidney was also measured as tumor necrosis factor- $\alpha$ (TNF- $\alpha$ ) in serum. Level of (TNF- $\alpha$ ) in diabetic untreated groups was increased as a result of diabetes, ROS, and DN.

Treatment of rats with (G T, PA and GT with PA) leads to a significant decrease in the level of (TNF- $\alpha$ ) which could be correlated to the improvement of the antioxidant enzymes and this was confirmed in the histopathology. Decreasing of (TNF- $\alpha$ ) indicates that the degree of inflammation was significantly reduced. All these results were in line with previous work.

\section{Conclusion}

As Diabetes mellitus is a serious metabolic disorder with micro and macro vascular complication that resulted in significant morbidity and mortality. So (GT), (PACs) $95 \%$ (Noxy life) and combination of them has been used to help normalize hyperglycemia level and delay sugar absorption so it delayed the complication of DM (diabetic nephropathy). The synergistic power which resulted from this combination make the result better than GT or PACs alone. As PACs one of the constituents of GT so it had better result, than (PACs) $95 \%$ (Noxy life) which also have strong antioxidants effect. 


\section{Acknowledgements}

This study was supported by Chemistry Department, Faculty of science, Biochemistry Department, Faculty of Medicine, Minia University. Elminia, Egypt.

\section{References}

1. KA Adeshara, AG Diwan, RS Tupe (2016) Diabetes and Complications: Cellular Signaling Pathways, Current Understanding and Targeted Therapies. Curr Drug Targets. 17(11): 1309-1328.

2. JC Arévalo-Lorido, J Carretero-Gómez, F García-Sánchez, Enrique Maciá-Botejara, José Manuel Ramiro-Lozano, et al. (2016) Secondary hyperparathyroidism prevalence and profile, between diabetic and non-diabetic patients with stage 3 to 4 chronic kidney disease attended in internal medicine wards. MiPTH study. Diabetes Metab Syndr 10(2 Suppl 1): S16-S21.

3. SS Badal, FR Danesh (2015) Diabetic Nephropathy: Emerging Biomarkers for Risk Assessment Diabetes. 64(9): 3063-3065.

4. H Nasri (2013) On the occasion of the world diabetes day 2013; diabetes education and prevention; a nephrology point of view.

J Ren Inj Prev 2(2): 31-32.

5. NJ Morrish, SL Wang, LK Stevens, J H Fuller, H Keen, et al. (2001) Mortality and causes of death in the WHO Multinational Study of Vascular Disease in Diabetes. Diabetologia 44(Suppl 2): S14-S21.

6. Ng KP, P Jain, PS Gill, G Heer, Townend J, et al. (2016) Results and lessons from the Spironolactone to Prevent Cardiovascular Events in Early-Stage Chronic Kidney Disease (STOP-CKD) randomised controlled trial. BM] Open 6(2): e010519.

7. AD Jagdale, LN Bavkar, TA More, MM Joglekar, AU Arvindekar, et al. (2016) Strong inhibition of the polyol pathway diverts glucose flux to protein glycation leading to rapid establishment of secondary complications in diabetes mellitusJ Diabetes Complications 30(3): 398-405.

8. ND Vaziri (2002) Human pharmacokinetic/pharmacodynamic profile of irbesartan: a new potent angiotensin II receptor antagonist. J Hypertens Supp 15(7): S15-S20.

9. X Luo, J Wu, S Jing, LJ Yan (2016) Hyperglycemic Stress and Carbon Stress in Diabetic Glucotoxicity. Aging and Disease 7(1): 90-110.

10. PC Singh, RK Gupta, LD Joshi (2001) Current Science 51: 105 -111.

11. RA Maritim sanders, A C Maritim, J B Watkins 3rd (2003) Diabetes, oxidative stress, and antioxidants: a review. J Biochem Mol Toxicol 17(1): 24-38.

12. B Alipoor, AH Rad (2012) A Review on the Therapeutical Effects of Tea. Asian J Clin Nutr 4: 1-15.

13. SM Chacko, PT Thambi, R Kuttan, I Nishigaki (2010) Beneficial effects of green tea: a literature review. Chin Med 5: 13-21.

14. K Hanhineva, R Törrönen, I Bondia-Pons, J Pekkinen, M Kolehmainen, et al. (2010) Impact of dietary polyphenols on carbohydrate metabolism. Int J Mol Sci 11(4): 1365-1402.
15. RA Dixon, DY Xie, SB Sharma (2005) Proanthocyanidins--a final frontier in flavonoid research?. New Phytol 165(1): 9-28.

16. M Mocros, AAR Sayed, A Bierhaus, Benito Yard, Rüdiger Waldherr, et al. (2002) Activation of Tubular Epithelial Cells in Diabetic Nephropath Diabetes 51(12): 3532-3544.

17. H Iso, Chigusa Date, Kenji Wakai, Mitsuru Fukui, Akiko Tamakoshi, et al. (2006) The relationship between green tea and total caffeine intake and risk for self-reported type 2 diabetes among Japanese adults. Ann Intern Med 144(8): 554-562.

18. Liu Ximing, Ha Zhou Jun, Rohdewald Peter (2004) French maritime pine bark extract Pycnogenol dose-dependently lowers glucose in type 2 diabetic patients. Diabetes Care 27(3): 839.

19. Schäfer Angelika, Högger Petra (2007) Oligomeric procyanidins of French maritime pine bark extract (Pycnogenol) effectively inhibit alpha glucosidase. Diabetes Res and Clin Pract 77(1): 41-46.

20. N Vivas, M Nonier, I Pianet, NathalieVivas de Gaulejac, ÉricFouquet, et al. (2006) Structure of extracted lignins from oak heartwood (Quercus petraea Liebl., Q. Robur L.). Comptes Rendus Chimie 9(9): 1221-1233.

21. F Caballero, E Gerez, A Batlle, Vasquez (2000) Preventive aspirin treatment of streptozotocin induced diabetes: blockage of oxidative status and revertion of heme enzymes inhibition. Chem biol Interact 126(3): 215-225.

22. N Sueoka, E Sueoka, Y Miyazaki, Sachiko Okabe, Masafumi Kurosumi, et al. (1998) Molecular Pathogenesis of Interstitial Pneumonitis eith Tnf-A Transgenic Mice. Cytokine 10(2): 124-131.

23. C Broca, V Breil, GC Cruciani, Michèle Manteghetti, Christine Rouault, et al. (2004) Insulinotropic agent ID-1101 (4-hydroxyisoleucine) activates insulin signaling in rat. Am J physiol Endocrinol Metab 287(3): 463.

24. R Leenen, AJC Roodenburg, LBM Tijburg, SA Wiseman, et al. (2000) A single dose of tea with or without milk increases plasma

antioxidant activity in humans. European Journal of Clinical Nutrition 54(1): 87-92.

25. P Cos, T De Bruyne, Hermans, S Apers, D Vanden Berghe, et al. (2004) Proanthocyanidins in health care: current and new trends. Curr Med Chem 11(10): 1345-1359.

26. SC Jones, HJ Saunders, CA Pollock (1999) High glucose increases growth and collagen synthesis in cultured human tubulointerstitial cells. Diabet Med 16(11): 932-938.

27. G Wolf, EG Neilson, S Goldfarb, Fuad N Ziyadeh (1997) The influence of glucose concentration on angiotensin II-induced hypertrophy of proximal tubular cells in culture. Biochem Biophys Res Commun 176(2): 902-909.

28. T Nishikawa, D Edelstein, XL Du, S Yamagishi, T Matsumura, et al. (2000) Normalizing mitochondrial superoxide production blocks three pathways of hyperglycaemic damage. Nature 404(6779): 787-790 